\title{
Fibroblast Growth Factor-2 and the HIV-1 Tat Protein Synergize in Promoting Bcl-2 Expression and Preventing Endothelial Cell Apoptosis: Implications for the Pathogenesis of AIDS-Associated Kaposi's Sarcoma
}

\author{
Cecilia Sgadari, ${ }^{1}$ Giovanni Barillari, ${ }^{1,2}$ Clelia Palladino, ${ }^{1}$ Stefania Bellino, ${ }^{1}$ \\ Brunella Taddeo, ${ }^{1,3}$ Elena Toschi, ${ }^{1}$ and Barbara Ensoli ${ }^{1}$ \\ ${ }^{1}$ National AIDS Center, Istituto Superiore di Sanità, 00161 Rome, Italy \\ ${ }^{2}$ Department of Experimental Medicine, University of Rome Tor Vergata, 00133 Rome, Italy \\ ${ }^{3}$ Marjorie B. Kovler Viral Oncology Laboratories, The University of Chicago, Chicago, IL 60637, USA
}

Correspondence should be addressed to Barbara Ensoli, barbara.ensoli@iss.it

Received 8 April 2011; Revised 18 July 2011; Accepted 24 July 2011

Academic Editor: Karlheinz Peter

Copyright (C) 2011 Cecilia Sgadari et al. This is an open access article distributed under the Creative Commons Attribution License, which permits unrestricted use, distribution, and reproduction in any medium, provided the original work is properly cited.

Kaposi's sarcoma (KS) is a vascular tumor frequently occurring in Human Immunodeficiency Virus- (HIV-) 1-infected individuals. Our previous work indicated that the angiogenic fibroblast growth factor (FGF)-2 and the Tat protein of HIV-1, both expressed in KS lesions of HIV-infected patients, synergize at inducing angioproliferative, KS-like lesions in mice. Here we show that the development of angioproliferative lesions promoted in mice by combined Tat and FGF-2 associates with an increase in the levels of expression of the antiapoptotic Bcl-2 protein. Upregulation of Bcl-2 expression by combined FGF-2 and Tat occurs also in vitro, and this protects human primary endothelial cells from programmed cell death. As Bcl-2 is expressed in human KS lesions in a fashion paralleling the progression of the disease, these findings suggest a molecular mechanism by which Tat and FGF-2 cooperate in KS maintenance and progression in HIV-infected individuals.

\section{Introduction}

KS arises as multiple patch, plaque, or nodular lesions, which are generally located on the skin or mucosas but can also involve visceral organs (reviewed in [1]).

Early-stage KS lesions resemble an inflammatory, granulation-type reaction, and they are characterized by abnormal angiogenesis, leukocyte infiltration, endothelial cell activation, edema and by the proliferation of endothelial-like, spindle-shaped cells which are considered to be the KS tumor cells (KS cells) [1].

The development of KS lesions is triggered by inflammatory mediators and growth factors [1], whose production can be induced or enhanced by the human herpesvirus-8 (HHV8 ), a viral agent infecting nearly all KS patients (reviewed in [2]).
Among the growth factors expressed in KS lesions, FGF-2 is key for KS development. Specifically, upon its production by KS cells or infiltrating leukocytes, FGF-2 stimulates the locomotion and growth of both endothelial and KS cells by paracrine and autocrine mechanisms, respectively [1]. Consistently, FGF-2 can directly promote the development of KS-like lesions in vivo $[3,4]$, and it mediates the formation of angioproliferative lesions induced by KS cell injection in nude mice [5].

Despite rare and slowly progressive in general population, KS becomes frequent and aggressive in HIV-infected individuals (Acquired Immune Deficiency Syndrome- [AIDS-] associated KS) [1].

In this regard, previous results indicated that the Tat protein of HIV-1 can act as a progression factor in AIDS-KS. In particular, Tat, a transactivator of HIV-1 gene expression 
which is essential for virus replication, is released by HIV-1 acutely infected $\mathrm{T}$ cells (reviewed in [6]). By engaging cell surface receptors belonging to the integrin family, extracellular Tat induces endothelial or KS cell locomotion and adhesion [6]. At the same time, Tat competes FGF-2 binding to the heparan-sulphate proteoglycans of the cell surface and extracellular matrix (ECM) [7]. In doing so, Tat can retrieve sequestered FGF-2 into a soluble, biologically active form which, in turn, promotes endothelial or KS cell growth [7].

While early-stage KS lesions have a polyclonal nature and may regress, late nodular KS lesions can evolve into a true sarcoma [1]. Noteworthy, at this stage of disease progression, KS lesions undergo a rapid growth in the presence of a low mitotic index [8]. This suggested that vascular cell survival could be prevalent in KS maintenance and progression.

In this context, the protein levels of $\mathrm{Bcl}-2$, a potent antagonist of programmed cell death (apoptosis), were found to be increased in late-stage, as compared to early-stage, lesions from all forms of KS [8-12]. Coexpression of Bcl-2 and endothelial cell markers $[9,10]$ indicates that Bcl-2 is upregulated in activated endothelial cells lining the newly formed, abnormal blood vessels characterizing KS lesions. Consistently, Bcl-2 up-regulation is associated with the reduction or absence of endothelial cell apoptosis $[8,9]$.

At the present time, however, little or nothing is known about the mechanisms of Bcl-2 induction in KS.

Since either Tat or FGF-2 has been shown to modulate Bcl-2 expression by a wide variety of cell types [13-21], herein we evaluated the effects of FGF-2 and Tat, alone or combined, on Bcl-2 expression in animal and in vitro experimental models previously employed to study AIDS-KS pathogenesis.

\section{Materials and Methods}

2.1. Reagents. Recombinant HIV-1 Tat protein (from the IIIB isolate) was obtained, purified, tested for biological activity, and handled as previously described [22]. Human recombinant FGF-2 was purchased from Roche Molecular Biochemicals (Indianapolis, IN). Bovine serum albumin (BSA, fraction $\mathrm{V}$ ), heparin (sodium salt, from porcine intestinal mucosa), gelatin (denatured collagen I, from bovine skin), and the chemicals employed for protein extraction were from Sigma (St. Louis, MO). Matrigel, a reconstituted basement membrane, and endothelial cell growth supplement (ECGS) were obtained from BD Bioscience (Bedford, MA). The phosphate buffered saline (PBS) solution, RPMI 1640 growth medium, and its supplements were from Invitrogen (Paisley, Scotland, UK).

2.2. Animal Studies. Recombinant FGF-2 and/or Tat protein $(1 \mu \mathrm{g}$ and $10 \mu \mathrm{g}$, resp.) were suspended in $0.2 \mathrm{~mL}$ of PBS$0.1 \%$ BSA, mixed with an equal volume of Matrigel and then injected subcutaneously into the lower back of Balb-c $\mathrm{nu} / \mathrm{nu}$ female mice (4-6-week old, Charles River Breeding Laboratories, Calco, Italy), as previously described [3, 4]. Control animals were inoculated with the same volume of Matrigel and the buffer (PBS-0.1\% BSA) employed to suspend FGF-2 or Tat. Seven days later, mice were sacrificed, and, at this time, the sites of injection were evaluated for the presence of macroscopic lesions $[3,4]$. Tissue samples were taken and fixed in formalin or frozen in OCT compound (Miles Laboratories, Naperville, IL). Slides obtained from formalin-fixed paraffin-embedded blocks were examined at the microscope after hematoxylin-eosin staining. Frozen tissue sections were fixed in acetone and stained with $0.4 \mu \mathrm{g} / \mathrm{mL}$ of anti-Bcl-2 rabbit polyclonal antibody (Santa Cruz Biotechnology, Santa Cruz, CA) by the peroxidase-antiperoxidase method (Dako) [3,4]. The percentage of positive cells was determined from the mean of 5 high-power fields (40X magnification) and expressed as the mean (minimum and maximal range) of values obtained. The care and use of mice were in accordance with the European Community guidelines.

2.3. Cell Cultures. Human umbilical vein endothelial cells (HUVECs) were obtained from Lonza (Verviers, Belgium), seeded on surfaces precoated with gelatin, and cultured in RPMI 1640 medium supplemented with 15\% fetal bovine serum (FBS), sodium pyruvate, L-glutamine, MEM essential and nonessential amino acids, heparin $(1 \mu \mathrm{g} / \mathrm{mL})$, and ECGS $(45 \mu \mathrm{g} / \mathrm{mL})$. Experiments were performed in the absence of ECGS or heparin.

2.4. Western Blot Analysis. At the end of each experiment, HUVECs were washed in ice-cold PBS, scraped off the flask, and lysed in $50 \mathrm{nM}$ Tris $\mathrm{pH} 7.5,1 \mathrm{mM}$ phenylmethylsulfonyl fluoride (PMSF), 2 mM EGTA, 10 mM DTT, $5 \mu \mathrm{g} / \mathrm{mL}$ aprotinin, $200 \mu \mathrm{g} / \mathrm{mL}$ leupeptin, and $0.15 \%$ triton $\mathrm{X} 100$. The protein content in the cell lysates was assayed with the Bradford reagent (Bio-Rad, Hercules,CA). Eight $\mu \mathrm{g}$ of proteins from each experimental condition were subjected to $12 \%$ sodium dodecyl sulfate-polyacrylamide gel electrophoresis followed by transfer onto nitrocellulose membrane (Amersham Pharmacia Biotech, Little Chalfont, Buckinghamshire, UK). Filters were rinsed in blocking buffer (5\% nonfat dry milk, $0.1 \%$ Tween-20 PBS), probed with anti-Bcl-2 monoclonal antibodies $(2 \mu \mathrm{g} / \mathrm{mL}$, Santa Cruz), incubated with horseradish peroxidase-conjugated goat antimouse secondary antibodies (Amersham), and developed with the use of the enhanced chemiluminescence (ECL) method (Amersham). Intensity of the Bcl-2-specific band was quantified by densitometry, using an Imaging Densitometer GS-700 and a Multi-Analyst software (Bio-Rad). To verify equal loading of protein in each lane, blots were reprobed with anti- $\beta$ actin monoclonal antibodies (Sigma).

2.5. Detection of Apoptosis. HUVECs were seeded on plates coated with gelatin or with $10 \mu \mathrm{g} / \mathrm{mL}$ of poly-2hydroxymethyl-methacrylate [poly(HEMA)] [23]. Cells were exposed to FGF-2, Tat, or their suspension buffer and then collected. The entity of cell death was determined by using two different assays.

The first was the Programmed Cell Death ELISA kit (Roche) which measures the amount of nucleosomes released in the cytoplasm of dying cells. Briefly, HUVECs 


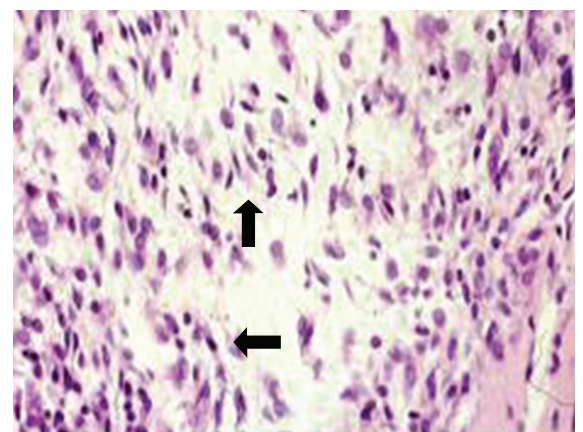

(a)

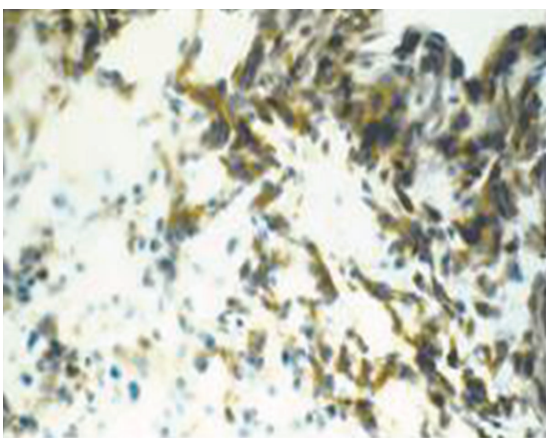

(d)

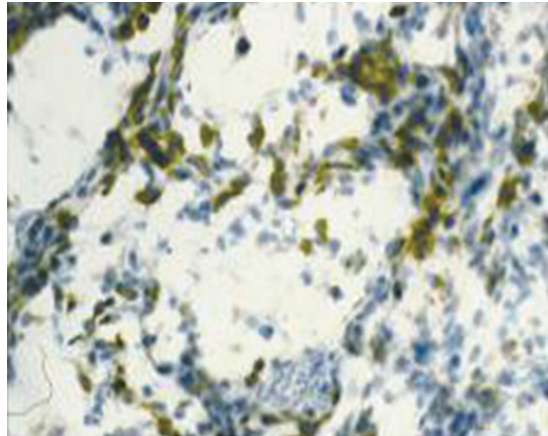

(b)

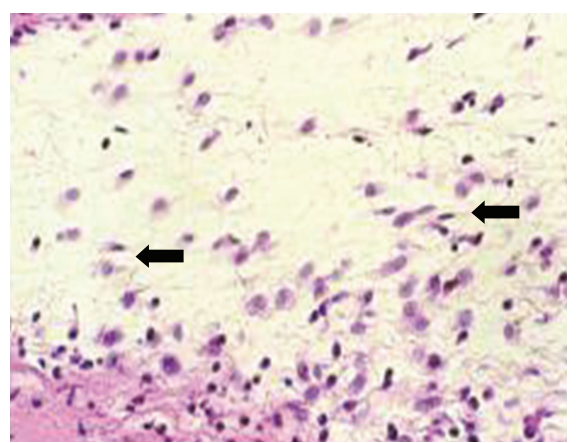

(e)

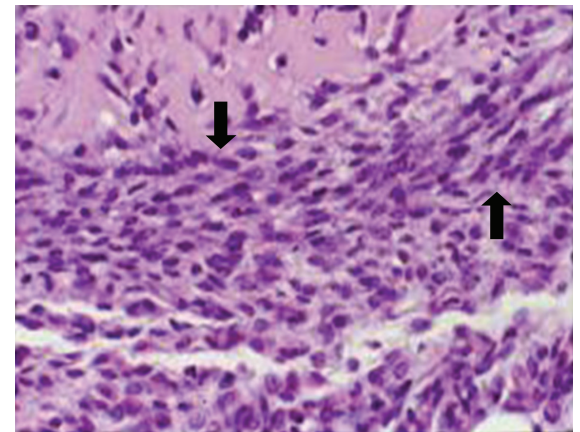

(c)

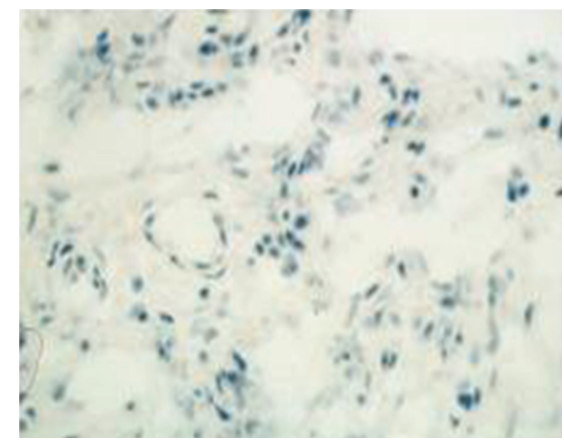

(f)

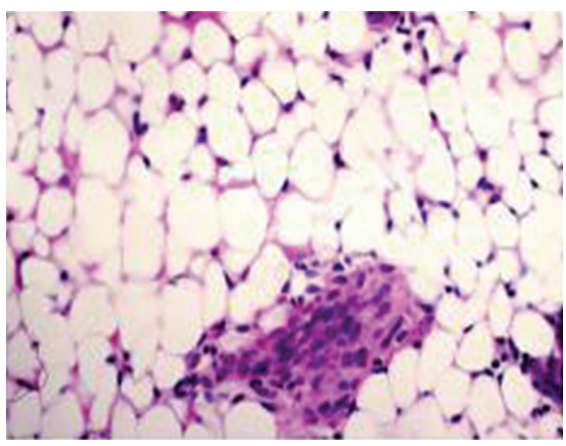

(g)

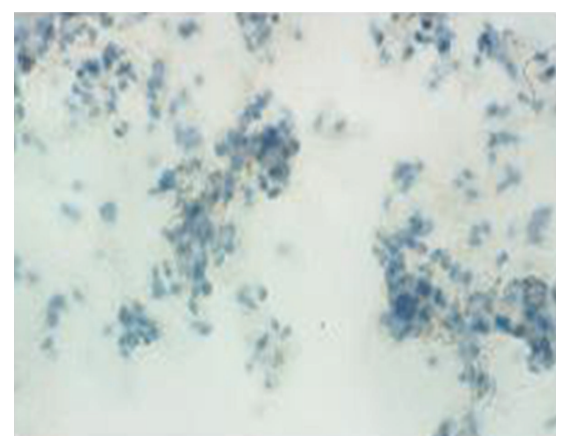

(h)

FIGURE 1: Induction of Bcl-2 expression in mice by FGF-2 and Tat. Mice were injected with $1 \mu \mathrm{g}$ of FGF-2 and/or $10 \mu \mathrm{g}$ of Tat, as described in Section 2. After 7 days tissue samples were taken at the injection sites and processed for histological examination by hematoxylin-eosin staining (left panels, 40X magnification). Tissue sections from 12 animals per group were stained with anti-Bcl-2 antibody (right panels, 40X magnification). Induction of KS-like lesions promoted by $1 \mu \mathrm{g}$ FGF-2 (a) was associated with Bcl-2 protein expression (b). The simultaneous inoculation of $1 \mu \mathrm{g}$ FGF-2 and $10 \mu \mathrm{g}$ Tat further increased both lesion development (c) and Bcl-2 expression (d). The inoculation of $10 \mu \mathrm{g}$ Tat alone induced only limited histological alterations (e) and no Bcl-2 protein expression (f) at the injection sites. Protein suspension buffer (PBS-0.1\% BSA) did not promote lesion development (g), nor Bcl-2 protein expression (h). Arrows point at some representative spindle cells of KS-like lesions.

were lysed, and the cytoplasmic fraction was recovered after centrifugation, and nucleosomes assayed as indicated by the manufacturer. Each sample was tested in duplicate.

The second method was the terminal deoxynucleotidyl transferase-mediated dUTP nick end labeling (TUNEL) assay. Briefly, HUVECs were spun on slides by cytospin, fixed in $4 \%$ paraformaldehyde, and the DNA strand breaks of apoptotic cells were identified in situ by TUNEL kit (Roche), according to the manufacturer's instructions. Fluoresceinated nucleotides incorporated in polymers by the terminal deoxynucleotidyl transferase-based enzymatic reaction were detected by immuno-histochemical staining using a mouse antifluorescein isothiocyanate (FITC) monoclonal antibody and the alkaline phosphatase-anti-alkaline phosphatase method (Dako) [3]. The percentage of positive, apoptotic cells was determined from the mean of 4 highpower fields.

2.6. Reverse Transcriptase-Polymerase Chain Reaction (RT$P C R)$. Total RNA was extracted from HUVECs with the 

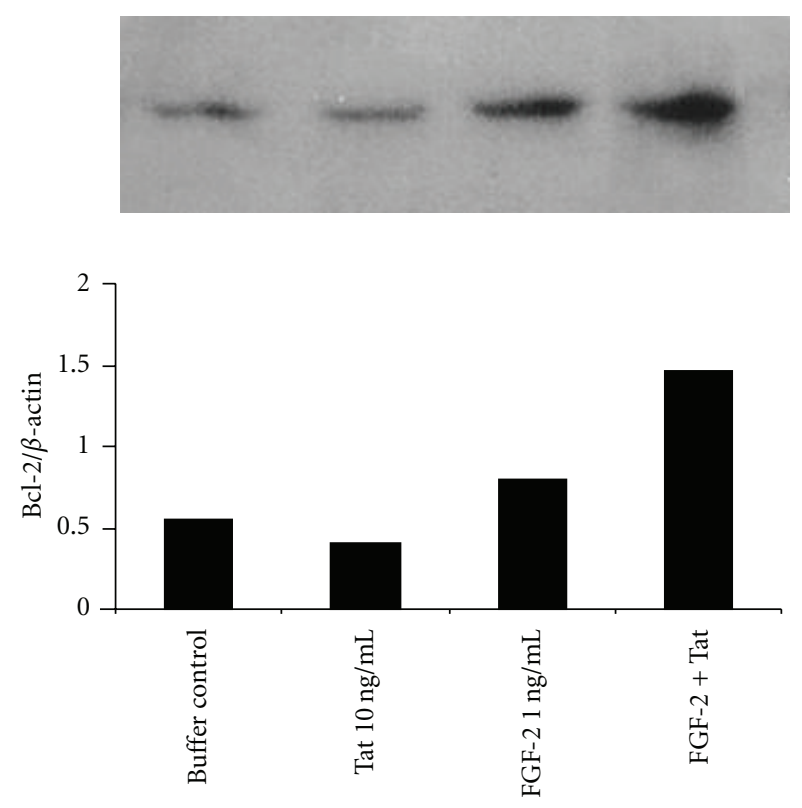

FIGURE 2: Induction of Bcl-2 protein expression by FGF-2 and/or Tat in human primary endothelial cells. HUVECs were cultured in the presence of Tat $(10 \mathrm{ng} / \mathrm{mL})$ and/or FGF-2 $(1 \mathrm{ng} / \mathrm{mL})$. HUVECs treated with the protein suspension buffer (PBS-0.1\% BSA) were used as controls. After 24 hours of culture, HUVECs were lysed, and equal amounts of total proteins were electrophoresed and analysed by Western blotting using monoclonal antibodies directed against human $\mathrm{Bcl}-2$. Blots were reprobed with anti- $\beta$ actin monoclonal antibodies to verify equal loading of protein in each lane. In the upper panel a representative Western blot for $\mathrm{Bcl}-2$ protein is shown. In the lower panel is its densitometric analysis, which is presented as the $\mathrm{Bcl}-2$ to $\beta$ actin ratio. Repeated experiments (two) gave similar results.

RNA assay Mini kit (Qiagen, Hilden, Germany) and further purified by three-round digestion with pancreatic DNAse I (10 IU/sample). Purified RNA $(0.5 \mu \mathrm{g})$ was retrotranscribed with the reverse transcription system kit (Promega, Madison, WI, USA) by incubating the reactions with hexanucleotide random primers for $10 \mathrm{~min}$ at room temperature, $30 \mathrm{~min}$ at $42^{\circ} \mathrm{C}$, and $30 \mathrm{~min}$ at $53^{\circ} \mathrm{C}$. After heat inactivation of the RT reaction, each sample was subjected to a low (pre-plateau) number of cycles of PCR (28 to 30) for $\beta$-actin with primer BA-1 [5'CATGTGCAAGGCCGGCTTCG-3', nucleotide (nt) 1137 to $1156]$, located in the first exon of the human $\beta$-actin gene, and primer BA-4 (5'-GAAGGTGTGGTGCCAGATTT- $3^{\prime}$, nt 1475 to 1494 ) designed in the second exon of the gene (nt enumeration as in GenBank M10277). These primers yield a $226 \mathrm{bp}$ cDNA amplicon; contaminant DNA is revealed by the appearance of a $357 \mathrm{bp}$ genomic amplicon. The amount of cDNA to be used for Bcl-2 PCR was determined after cDNA normalization by pre-plateau $\beta$-actin PCR. The normalized samples were then subjected to 35 cycles of PCR for Bcl2. Bcl-2 primers were $5^{\prime}$-TCGCCCTGGTGGACAACA-3' (nt 1957 to 1975) and $5^{\prime}$-TGACTTCACTTGTGGCTCAGA-3' (nt 2183 to 2163) (nt enumeration as in GenBank M13994). Conditions for Bcl-2 amplification were as follows: $4 \mathrm{~min}$ at $94^{\circ} \mathrm{C}$, followed by 35 cycles of denaturation at $94^{\circ} \mathrm{C}$ for $1.5 \mathrm{~min}$, annealing at $58^{\circ} \mathrm{C}$ for $1.5 \mathrm{~min}$, and extension at $72^{\circ} \mathrm{C}$ for 2 min. Negative control reactions lacking DNA template were always performed in parallel to control for sample to sample contamination.

PCR-amplified products were separated onto a $1.8 \%$ agarose gel, blotted on nylon membrane, and hybridized to a $32[\mathrm{P}]$-labeled oligonucleotide probe internal to the amplicon by standard techniques. After extensive washing, filters were exposed to X-ray films and the intensity of the bands quantified by Instant Imager (Packard Instruments, Downers, IL, USA).

2.7. Statistical Methods. Analysis of the results from animal studies was performed according the test on equality of proportion by STATA program. Statistical evaluation of the in vitro data was performed by the analysis of variance model (ANOVA) with Tukey-Kramer adjustment for multiple comparisons, using the SAS software, version 9.1 (SAS Institute, Cary, NC, USA). A $P$-value of $<0.05$ was considered as significant.

\section{Results}

3.1. Induction of Angioproliferative Lesions by FGF-2 Is Associated with Bcl-2 Expression, and Both Are Enhanced by Tat. Initial experiments investigated FGF-2 or Tat effects on Bcl-2 expression in vivo.

Our previous work tested the dose response effects that FGF-2 or Tat $(0.1-100 \mu \mathrm{g})$ has on the induction of histological features characterizing KS lesions in vivo $[3,4,24]$. Starting from those findings, we employed the Tat and/or FGF-2 concentrations particularly effective at promoting the development of macroscopic KS-like lesions in mice.

Specifically, nude mice were injected with $1 \mu \mathrm{g}$ of FGF2 and/or $10 \mu \mathrm{g}$ of Tat. Control animals were inoculated with the protein suspension buffer (PBS-0.1\% BSA). After 7 days, mice were sacrificed and the sites of injection were examined for the presence of angioproliferative lesions [3, 4]. Tissue samples were excised and processed for histology and Bcl-2 immuno-histochemistry.

As shown in Figure 1, FGF-2 injection resulted in the development of macroscopic angioproliferative KS-like lesions. Specifically, 19 out of the 43 mice injected with FGF-2 (=44\%, $P<0.001)$ developed KS-like lesions. This was associated with the appearance of spindle-shaped cells (Figure 1(a)), which are the histological hallmark of human KS lesions [1], and with the induction of Bcl-2 expression (Figure 1(b)). In particular, 32\% (range 19-49) of the cells present in the lesions were positive for Bcl-2.

Noteworthy, the simultaneous inoculation of FGF-2 and Tat further increased both lesion development and Bcl-2 expression. In particular, out of the 31 mice injected with combined FGF-2 and Tat, $22(=71 \%, P<0.05)$ developed macroscopic lesions (Figure 1(c)), in which $47 \%$ (range $22-$ 67 ) of the cells were Bcl-2 positive (Figure 1(d)).

In contrast, none of the 17 mice injected with Tat alone, and none of the 70 mice injected with the protein 


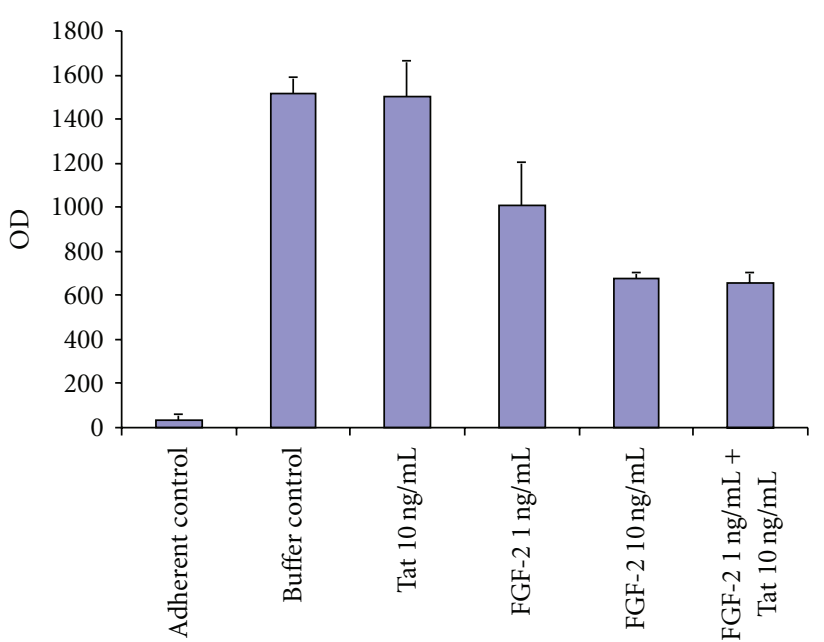

(a)

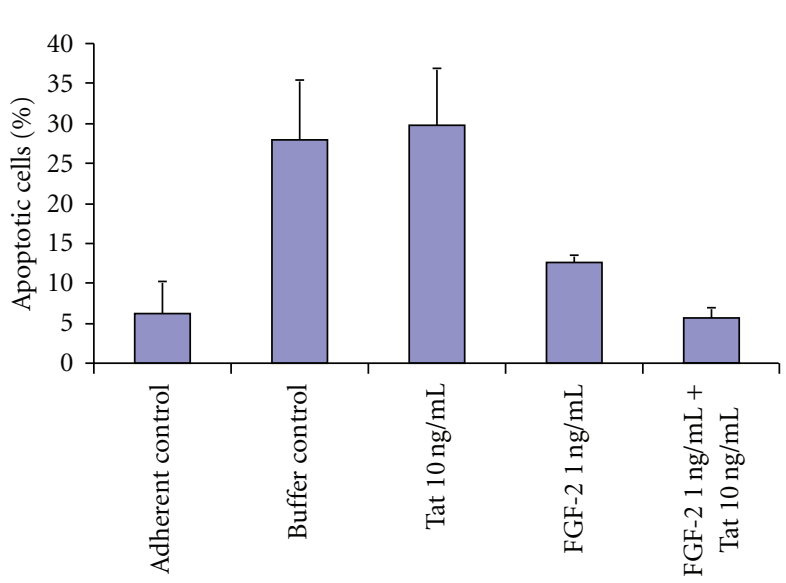

(b)

FIGURE 3: Effect of FGF-2 and Tat on human endothelial cell anoikis. HUVECs were seeded onto poly- (HEMA)-coated plates and incubated for $6 \mathrm{~h}$ with FGF-2 (1 or $10 \mathrm{ng} / \mathrm{mL})$ and/or Tat $(10 \mathrm{ng} / \mathrm{mL})$, controlled by their dilution buffer (PBS- $0.1 \%$ BSA). HUVECs plated onto gelatin were the negative control for apoptosis. In (a) are the results from the ELISA test determining the amount of nucleosomes in HUVECs cytoplasm. The mean OD readings from 4 independent experiments (+SD) are presented. In (b) HUVECs apoptosis was evaluated by TUNEL test. The mean percentage $(+S D)$ of apoptotic cells was determined from 4 high-power fields (40X magnification) of 3 independent experiments.

suspension buffer (PBS-0.1\% BSA), developed macroscopic lesions (Figures $1(\mathrm{e})$ and $1(\mathrm{~g})$, resp.). For both experimental conditions, Bcl-2 was not expressed at the sites of injection (Figures $1(\mathrm{f})$ and $1(\mathrm{~h})$, resp.).

To confirm these in vivo results, the effects of FGF2 and Tat on Bcl-2 expression were evaluated in cultured human primary endothelial cells. To this end, HUVECs were exposed for 24 hours to FGF-2 and/or Tat (controlled by their suspension buffer), and Bcl-2 protein levels were examined by Western blot analysis. As shown in Figure 2, FGF-2 increased $\mathrm{Bcl}-2$ protein expression, while Tat alone had no effect. However, when Tat was combined with FGF-2, Bcl-2 protein levels further increased, confirming the in vivo data.

3.2. FGF-2 and Tat Protect Nonadherent Endothelial Cells from Apoptosis via the Upregulation of Bcl-2 Expression. Bcl-2 can protect endothelial cells from anoikis, the process where adherent cells die when they lose contact with the ECM $[25,26]$.

In view of our in vivo and in vitro results, additional work was performed in order to evaluate FGF-2 or Tat effect on endothelial cell anoikis. To this end we seeded HUVECs onto plates coated with poly- (HEMA), a compound preventing cellular adhesion [23]. Then, we incubated the cells for $6 \mathrm{~h}$ with FGF-2, Tat, or their suspension buffer. The entity of cell death was determined by measuring, in HUVECs cytoplasm, the content of nucleosomes, histone complex of low-molecular-weight DNA fragments resulting from the cleavage of apoptotic cell genome [27]. Adherent HUVECs plated onto gelatin were the negative control for cell death $[25,26]$.
As expected, HUVECs did not adhere onto poly(HEMA)-coated surfaces, and this was followed by a dramatic increase of nucleosome content in the cytoplasm of nonadherent, as compared to adherent, HUVECs $(P<$ 0.0001) (Figure 3(a)). Noteworthy, exposure of nonadherent HUVECs to 1 or $10 \mathrm{ng} / \mathrm{mL}$ FGF- 2 reduced the amount of cytoplasmic nucleosomes by $30 \%$ and $50 \%$, respectively $(P<$ 0.0001) (Figure 3(a)). Although Tat alone had no effect, when it was combined with $1 \mathrm{ng} / \mathrm{mL}$ of FGF-2, it decreased the amount of cytoplasmic nucleosomes to levels as found in HUVECs treated with $10 \mathrm{ng} / \mathrm{mL}$ FGF-2 (Figure 3(a)). Thus, Tat increased FGF-2 capability of rescuing endothelial cell apoptosis $(P=0.0102)$.

The TUNEL assay confirmed these results. Specifically, in nonadherent conditions, $1 \mathrm{ng} / \mathrm{mL}$ of FGF-2 diminished the number of apoptotic HUVECs by $55 \%$ when employed alone $(P=0.0490)$ and by $80 \%$ when combined with $10 \mathrm{ng} / \mathrm{mL}$ of Tat $(P=0.0025)$ (Figure 3(b)).

To investigate whether the increase of endothelial cell survival promoted by FGF-2 and Tat in nonadherent conditions was accompanied by a modulation of Bcl-2 expression, Bcl-2 mRNA levels were evaluated in HUVECs under the different experimental conditions described above.

Results from RT-PCR assays indicated that Bcl-2 mRNA levels decreased by $-53 \%$ in nonadherent HUVECs, as compared to the adherent control $(P=0.0396)$ (Figure 4). When nonadherent HUVECs were exposed to $10 \mathrm{ng} / \mathrm{mL}$ of FGF-2, Bcl-2 mRNA expression was rescued to levels as expressed by adherent HUVECs $(P=0.05)$ (Figure 4). Although Tat alone had no effect, when it was combined with $1 \mathrm{ng} / \mathrm{mL}$ of FGF-2, the expression of Bcl-2 was restored to the levels detected in adherent HUVECs $(P=0.0480)$ (Figure 4). 

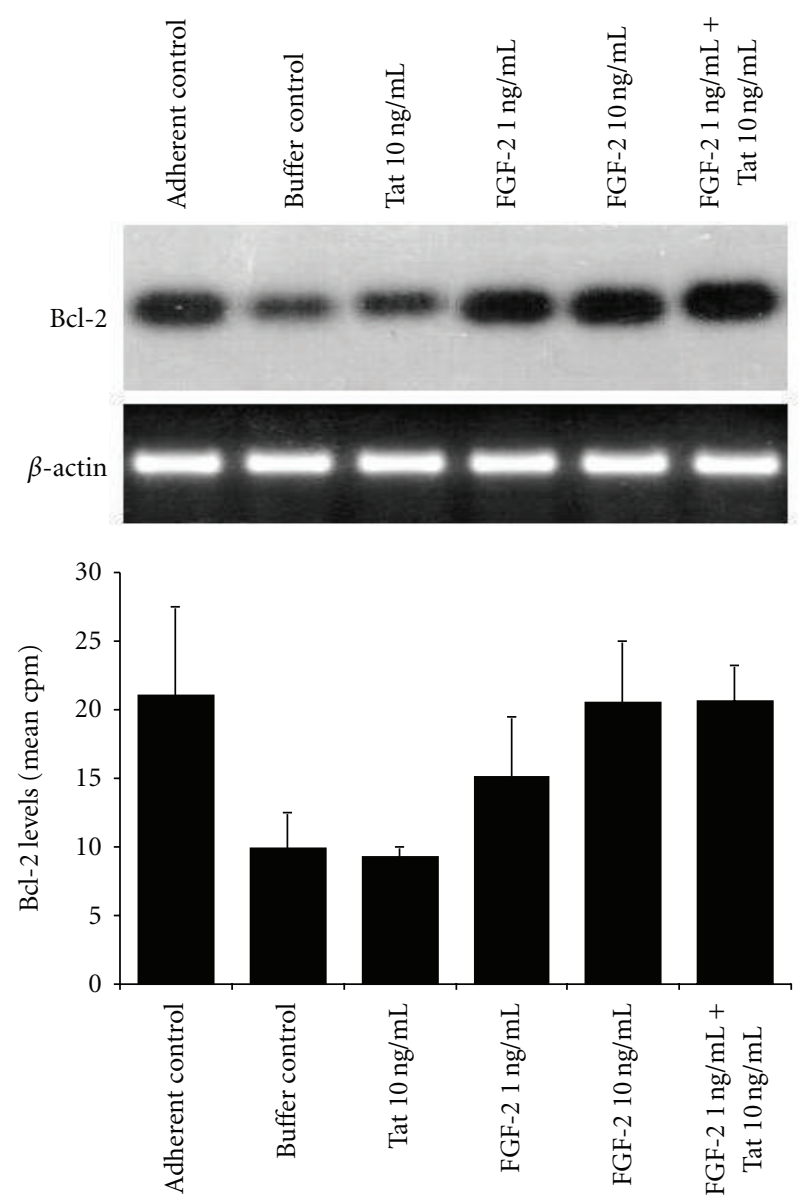

Figure 4: Protection of human endothelial cells from anoikis by FGF-2 alone or combined with Tat parallels the up-regulation of $\mathrm{Bcl}-2$ expression. HUVECs were treated as described in the legend of Figure 2. Total RNA was extracted from the cells, and the Bcl-2 mRNA levels were analyzed by a housekeeping gene normalized RT-PCR assay. In the upper panel is the Southern blot hybridization of PCR products from a representative RTPCR experiment performed with primers specific for Bcl-2. In the central panel is the $\beta$-actin RT-PCR amplification of the samples, showing that normalization of cDNA content resulted in $\beta$-actin PCR bands of identical size. In the lower panel is the quantification of Bcl-2 hybridization bands by Instant Imager from 3 independent experiments (average $+\mathrm{SD}$ ).

\section{Discussion}

In healthy tissues, undesired angiogenesis is switched off through the induction of endothelial cell apoptosis $[25,28]$. This can be triggered by conditions, such as the lack of angiogenic growth factors, or the inhibition of endothelial cell adhesion onto the ECM, which downregulate endothelial cell expression of antiapoptotic molecules [25, 28].

Among the latter, Bcl-2 is very effective at favouring the angiogenic process. In particular, Bcl-2 is overexpressed by endothelial cells of the newly formed blood vessels nourishing the growing tumor $[29,30]$.

In agreement with the fact that $\mathrm{Bcl}-2$ expression can lead to inappropriate endothelial cell survival and abnormal angiogenesis $[25,28]$, clinical evidence suggests that the deregulation of Bcl-2 expression could play a role in the maintenance and progression of KS. In fact, $\mathrm{Bcl}-2$ protein levels augment in late-stage, as compared to early-stage, KS lesions, and this parallels a decrease in vascular cell apoptosis [8-12].

A role for $\mathrm{Bcl}-2$ in $\mathrm{KS}$ progression is supported also by the efficacy of the Bcl-2 inhibitor paclitaxel in KS patients [31], confirming previous work performed with animal models of KS [32].

Here, we evaluated whether FGF-2 or HIV-1 Tat, two key AIDS-KS pathogenetic factors, could affect Bcl-2 expression in vivo and in vitro.

Results indicate that FGF-2 injection into mice results in the induction of $\mathrm{Bcl}-2$ expression and that this associates with the development of angioproliferative, KS-like lesions.

Regarding Tat, it has no effects on Bcl-2 expression when present alone. Tat protein is known to enter cells and activate the expression of cellular genes [6]. In particular, Tat was shown to up-regulate Bcl-2 expression by monocytes, albeit at higher concentrations than the ones we used here [33]. However, the possibility that in our experimental model Tat could directly activate Bcl-2 expression is excluded by our results indicating that Tat alone is not capable of promoting KS-like lesions in mice, rescuing endothelial cell apoptosis or inducing Bcl-2 expression by these cells. The contrasting data that others obtained in monocytes could depend on the different cell type they utilized. The fact that Tat effects are cell-type dependent is strongly supported by previous findings indicating that Tat promotes apoptosis in other cell systems [34-39].

In contrast, when Tat is combined with FGF-2, it strongly enhances FGF-2 effects on $\mathrm{Bcl}-2$, this paralleling a dramatic increase in the formation of angioproliferative lesions in mice.

These findings are consistent with all the other activities that Tat exerts on endothelial cells, which require FGF-2 presence in order to respond to Tat either in vitro or in vivo $[3,4,7]$. In this regard, Tat and FGF-2 synergy is likely to depend on FGF-2 capability of inducing the expression of the $\alpha_{v} \beta_{3}$ and $\alpha_{5} \beta_{1}$ integrins, which, in turn, function as Tat receptors $[3,4,7,40]$. On the other side, Tat can maintain FGF-2 into a highly active and readily available form, thus amplifying its biological effects [7].

Previous studies indicated that the cross-talk between the integrins and growth factor receptors triggers a signalling cascade which is relevant for endothelial cell survival and growth $[25,28]$. In this regard, it has to be reminded that signalling pathways leading to endothelial cell survival are activated upon Tat binding to the integrins, being further enhanced when FGF-2 is present in the environment [41]. In this context, our previous work indicated that induction of KS-like lesions by combined FGF-2 and Tat is reproduced by combined FGF-2 and the integrin-binding Tat RGD peptide (Tat 65-80), but not by mutated Tat KGE peptide [4].

In agreement with these findings, here we have reported that the induction of Bcl-2 expression by FGF-2 and Tat can prevent the death of endothelial cells resulting from the inhibition of their adhesive interaction with the ECM. 
Altogether, these results suggest a pathway for Bcl-2 induction and a molecular mechanism by which the simultaneous presence of Tat and FGF-2 could promote KS maintenance and progression in HIV-1-infected individuals. Since Tat and FGF-2 are expressed in AIDS-KS lesions together with Bcl-2 [1,3], these findings appear to be of biological relevance.

Finally, as $\mathrm{Bcl}-2$ diverts vascular cells from apoptosis and prolongs their survival $[21,29,30,42]$, its expression in advanced KS, coupled with a deregulated cellular proliferation by HIV, HHV8, and cellular factors [1,2], may result in KS maintenance and/or the progression of the early angiohyperplastic KS lesions into a true sarcoma. This hypothesis is supported by our recent observation that both FGF-2 and Tat can increase in KS cells the activity of the telomerase, an enzyme allowing cells to escape replicative senescence and to proliferate indefinitely $[43,44]$.

\section{Conclusions}

Our results indicate that FGF-2 and HIV-1 Tat synergize at inducing Bcl-2 expression and that this is accompanied by the inappropriate survival of endothelial cells and by the development of angioproliferative lesions. These findings suggest a molecular mechanism for the deregulated $\mathrm{Bcl}-2$ expression observed in AIDS-KS lesions and confirm that Bcl-2 may represent a key target for therapeutic intervention of KS.

\section{Acknowledgments}

This work was supported by grants from the Italian Foundation for Cancer Research (FIRC) and the Italian Ministry of Health to B. Ensoli. They thank Mrs. Guendalina Fornari Luswergh (National AIDS Center) for editorial assistance.

\section{References}

[1] B. Ensoli, C. Sgadari, G. Barillari, M. C. Sirianni, M. Stürzl, and P. Monini, "Biology of Kaposi's sarcoma," European Journal of Cancer, vol. 37, no. 10, pp. 1251-1269, 2001.

[2] P. S. Moore and Y. Chang, "Kaposi's sarcoma-associated herpesvirus immunoevasion and tumorigenesis: two sides of the same coin?" Annual Review of Microbiology, vol. 57, pp. 609-639, 2003.

[3] B. Ensoli, R. Gendelman, P. Markham et al., "Synergy between basic fibroblast growth factor and HIV-1 Tat protein in induction of Kaposi's sarcoma," Nature, vol. 371, no. 6499, pp. 674-680, 1994.

[4] G. Barillari, C. Sgadari, C. Palladino et al., "Inflammatory cytokines synergize with the HIV-1 Tat protein to promote angiogenesis and Kaposi's sarcoma via induction of basic fibroblast growth factor and the $\alpha(\mathrm{v}) \beta 3$ integrin," Journal of Immunology, vol. 163, no. 4, pp. 1929-1935, 1999.

[5] B. Ensoli, P. Markham, V. Kao et al., "Block of AIDS-Kaposi's sarcoma (KS) cell growth, angiogenesis, and lesion formation in nude mice by antisense oligonucleotide targeting basic fibroblast growth factor. A novel strategy for the therapy of KS," Journal of Clinical Investigation, vol. 94, no. 5, pp. 17361746, 1994.
[6] G. Barillari and B. Ensoli, "Angiogenic effects of extracellular human immunodeficiency virus type 1 Tat protein and its role in the pathogenesis of AIDS-associated Kaposi's sarcoma," Clinical Microbiology Reviews, vol. 15, no. 2, pp. 310-326, 2002.

[7] G. Barillari, C. Sgadari, V. Fiorelli et al., "The Tat protein of human immunodeficiency virus type-1 promotes vascular cell growth and locomotion by engaging the $\alpha 5 \beta 1$ and $\alpha \mathrm{v} \beta 3$ integrins and by mobilizing sequestered basic fibroblast growth factor," Blood, vol. 94, no. 2, pp. 663-672, 1999.

[8] E. Kaaya, E. Castanos-Velez, T. Heiden et al., "Proliferation and apoptosis in the evolution of endemic and acquired immunodeficiency syndrome-related Kaposi's sarcoma," Medical Oncology, vol. 17, no. 4, pp. 325-332, 2000.

[9] C. B. Morris, R. Gendelman, A. J. Marrogi et al., "Immunohistochemical detection of Bcl-2 in AIDS-associated and classical Kaposi's sarcoma," American Journal of Pathology, vol. 148, no. 4, pp. 1055-1063, 1996.

[10] S. Suster, C. Fisher, C. A. Moran, and A. M. Rywlin, "Expression of bcl-2 oncoprotein in benign and malignant spindle cell tumors of soft tissue, skin, serosal surfaces, and gastrointestinal tract," American Journal of Surgical Pathology, vol. 22, no. 7, pp. 863-872, 1998.

[11] P. Pillay, R. Chetty, and R. Reddy, "Bcl-2 and p53 immunoprofile in Kaposi's sarcoma," Pathology and Oncology Research, vol. 5, no. 1, pp. 17-20, 1999.

[12] M. T. Fernández-Figueras, L. Puig, A. Fernández-Vasalo, M. Esquius, M. A. Montera, and A. Ariza, "Immunohistochemical detection of Bcl-2 in Kaposi's sarcoma lesions varies according to histopathologic stage, whereas expression of $\mathrm{Bcl}-\mathrm{x}$ and Mcl-1 differs according to human immunodeficiency virus serologic status of patients," Modern Pathology, vol. 13, no. 4, pp. $438-445,2000$.

[13] G. Zauli, D. Gibellini, A. Caputo et al., "The human immunodeficiency virus type-1 Tat protein upregulates Bcl-2 gene expression in Jurkat T-cell lines and primary peripheral blood mononuclear cells," Blood, vol. 86, no. 10, pp. 3823-3834, 1995.

[14] K. J. Sastry, M. C. Marin, P. N. Nehete, K. McConnell, A. K. El-Naggar, and T. J. McDonnell, "Expression of human immunodeficiency virus type I tat results in downregulation of bcl-2 and induction of apoptosis in hematopoietic cells," Oncogene, vol. 13, no. 3, pp. 487-493, 1996.

[15] Z. Wang, G. F. Morris, J. C. Reed, G. D. Kelly, and C. B. Morris, "Activation of $\mathrm{Bcl}-2$ promoter-directed gene expression by the human immunodeficiency virus type-1 Tat protein," Virology, vol. 257, no. 2, pp. 502-510, 1999.

[16] O. E. Pardo, A. Arcaro, G. Salerno, S. Raguz, J. Downward, and M. J. Seckl, "Fibroblast growth factor-2 induces translational regulation of Bcl-XL and Bcl-2 via a MEK-dependent pathway: correlation with resistance to etoposide-induced apoptosis," Journal of Biological Chemistry, vol. 277, no. 14, pp. 1204012046, 2002.

[17] S. H. Teh, A. K. Hill, D. A. Foley, E. W. McDermott, N. J. O'Higgins, and L. S. Young, "COX inhibitors modulate bFGFinduced cell survival in MCF-7 breast cancer cells," Journal of Cellular Biochemistry, vol. 91, no. 4, pp. 796-807, 2004.

[18] M. Saunders, M. B. Eldeen, L. Del Valle et al., "p73 modulates HIV-1 Tat transcriptional and apoptotic activities in human astrocytes," Apoptosis, vol. 10, no. 6, pp. 1419-1431, 2005.

[19] C. O’Driscoll, D. Wallace, and T. G. Cotter, "bFGF promotes photoreceptor cell survival in vitro by PKA-mediated inactivation of glycogen synthase kinase $3 \beta$ and CREB-dependent Bcl-2 up-regulation," Journal of Neurochemistry, vol. 103, no. 3, pp. 860-870, 2007. 
[20] M. Ohshima, Y. Yamaguchi, K. Kappert, P. Micke, and K. Otsuka, "bFGF rescues imatinib/STI571-induced apoptosis of sis-NIH3T3 fibroblasts," Biochemical and Biophysical Research Communications, vol. 381, no. 2, pp. 165-170, 2009.

[21] L. Tu, L. Dewachter, B. Gore et al., "Autocrine fibroblast growth factor-2 signaling contributes to altered endothelial phenotype in pulmonary hypertension," American Journal of Respiratory Cell and Molecular Biology, vol. 45, no. 2, pp. 311322, 2011.

[22] E. Fanales-Belasio, S. Moretti, V. Fiorelli et al., "HIV-1 tat addresses dendritic cells to induce a predominant th1-type adaptive immune response that appears prevalent in the asymptomatic stage of infection," Journal of Immunology, vol. 182, no. 5, pp. 2888-2897, 2009.

[23] J. Munoz, Y. Zhou, and H. W. Jarrett, "LG4-5 domains of laminin-211 binds $\alpha$-dystroglycan to allow myotube attachment and prevent anoikis," Journal of Cellular Physiology, vol. 222, no. 1, pp. 111-119, 2010.

[24] E. Toschi, G. Barillari, C. Sgadari et al., "Activation of matrix-metalloproteinase-2 and membrane-type-1-matrixmetalloproteinase in endothelial cells and induction of vascular permeability in vivo by human immunodeficiency virus1 tat protein and basic fibroblast growth factor," Molecular Biology of the Cell, vol. 12, no. 10, pp. 2934-2946, 2001.

[25] J. B. Michel, "Anoïkis in the cardiovascular system: known and unknown extracellular mediators," Arteriosclerosis, Thrombosis, and Vascular Biology, vol. 23, no. 12, pp. 2146-2154, 2003.

[26] A. P. Gilmore, "Anoikis," Cell Death and Differentiation, vol. 12, no. 2, pp. 1473-1477, 2005.

[27] C. Jiang, Z. Wang, H. Ganther, and J. Lu, "Caspases as key executors of methyl selenium-induced apoptosis (anoikis) of DU-145 prostate cancer cells," Cancer Research, vol. 61, no. 7, pp. 3062-3070, 2001.

[28] S. A. Eccles, "Parallels in invasion and angiogenesis provide pivotal points for therapeutic intervention," International Journal of Developmental Biology, vol. 48, no. 5-6, pp. 583-598, 2004.

[29] J. E. Nör, J. Christensen, J. Liu et al., "Up-regulation of Bcl2 in microvascular endothelial cells enhances intratumoral angiogenesis and accelerates tumor growth," Cancer Research, vol. 61, no. 5, pp. 2183-2188, 2001.

[30] Y. Sakai, S. Goodison, S. Kusmartsev et al., "Bcl-2 mediated modulation of vascularizationin prostate cancer xenografts," Prostate, vol. 69, no. 5, pp. 459-470, 2009.

[31] M. Cianfrocca, S. Lee, J. Von Roenn et al., "Randomized trial of paclitaxel versus pegylated liposomal doxorubicin for advanced human immunodeficiency virus-associated Kaposi sarcoma: evidence of symptom palliation from chemotherapy," Cancer, vol. 116, no. 16, pp. 3969-3977, 2010.

[32] C. Sgadari, E. Toschi, C. Palladino et al., "Mechanism of paclitaxel activity in Kaposi's sarcoma," Journal of Immunology, vol. 165, no. 1, pp. 509-517, 2000.

[33] L. Zheng, Y. Yang, L. Guocai, C. D. Pauza, and M. S. Salvato, "HIV Tat protein increases Bcl-2 expression in monocytes which inhibits monocyte apoptosis induced by tumor necrosis factor-alpha-related apoptosis-induced ligand," Intervirology, vol. 50, no. 3, pp. 224-228, 2007.

[34] E. A. Eugenin, J. E. King, A. Nath et al., "HIV-tat induces formation of an LRP-PSD-95-NMDAR-nNOS complex that promotes apoptosis in neurons and astrocytes," Proceedings of the National Academy of Sciences of the United States of America, vol. 104, no. 9, pp. 3438-3443, 2007.

[35] S. Jajoo, D. Mukherjea, G. J. Brewer, and V. Ramkumar, "Pertussis toxin B-oligomer suppresses human immunodeficiency virus-1 Tat-induced neuronal apoptosis through feedback inhibition of phospholipase C- $\beta$ by protein kinase C," Neuroscience, vol. 151, no. 2, pp. 525-532, 2008.

[36] C. J. Li, D. J. Friedman, C. Wang, V. Metelev, and A. B. Pardee, "Induction of apoptosis in uninfected lymphocytes by HIV-1 Tat protein,” Science, vol. 268, no. 5209, pp. 429-431, 1995.

[37] S. F. Purvis, J. W. Jacobberger, R. M. Sramkoski, A. H. Patki, and M. M. Lederman, "HIV type 1 Tat protein induces apoptosis and death in Jurkat cells," AIDS Research and Human Retroviruses, vol. 11, no. 4, pp. 443-450, 1995.

[38] L. Qi, L. Gang, K. W. Hang et al., "Programmed neuronal cell death induced by HIV-1 tat and methamphetamine," Microscopy Research and Technique. In press.

[39] G. Zauli, D. Gibellini, D. Milani et al., "Human immunodeficiency virus type 1 Tat protein protects lymphoid, epithelial, and neuronal cell lines from death by apoptosis," Cancer Research, vol. 53, no. 18, pp. 4481-4485, 1993.

[40] G. Barillari, R. Gendelman, R. C. Gallo, and B. Ensoli, "The Tat protein of human immunodeficiency virus type 1, a growth factor for AIDS Kaposi sarcoma and cytokineactivated vascular cells, induces adhesion of the same cell types by using integrin receptors recognizing the RGD amino acid sequence," Proceedings of the National Academy of Sciences of the United States of America, vol. 90, no. 17, pp. 7941-7945, 1993.

[41] E. Toschi, I. Bacigalupo, R. Strippoli et al., "HIV-1 Tat regulates endothelial cell cycle progression via activation of the Ras/ERK MAPK signaling pathway," Molecular Biology of the Cell, vol. 17, no. 4, pp. 1985-1994, 2006.

[42] S. Kondo, D. Yin, T. Aoki, J. A. Takahashi, T. Morimura, and J. Takeuchi, "bcl-2 gene prevents apoptosis of basic fibroblast growth factor-deprived murine aortic endothelial cells," Experimental Cell Research, vol. 213, no. 2, pp. 428-432, 1994.

[43] G. Barillari, O. Franzese, A. Comandini, E. Bonmassar, and B. Ensoli, "Spindle cells from AIDS-associated Kaposi's sarcoma lesions express telomerase activity that is enhanced by Kaposi's sarcoma progression factors," Oncology Reports, vol. 24, no. 1, pp. 219-223, 2010.

[44] G. Barillari, O. Franzese, A. Iovane, and B. Ensoli, "Spindle cells from acquired immune deficiency syndrome-associated Kaposi's sarcoma lesions express telomerase activity directly relating to the RNA levels of fibroblast growth factor-2," International Journal of Cancer, vol. 127, no. 10, pp. 2487$2489,2010$. 


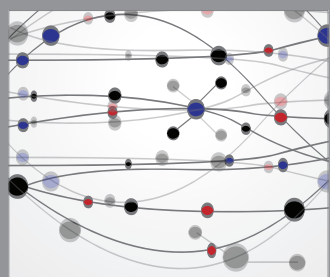

The Scientific World Journal
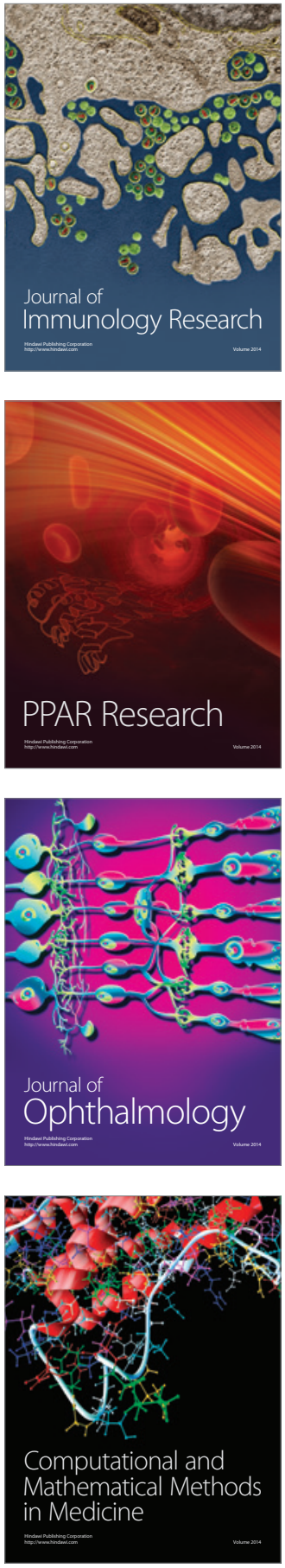

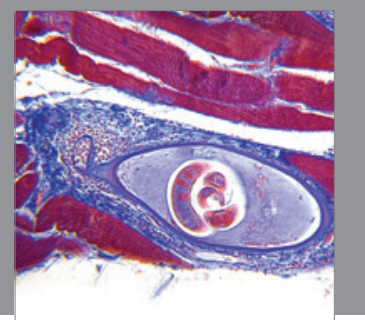

Gastroenterology

Research and Practice
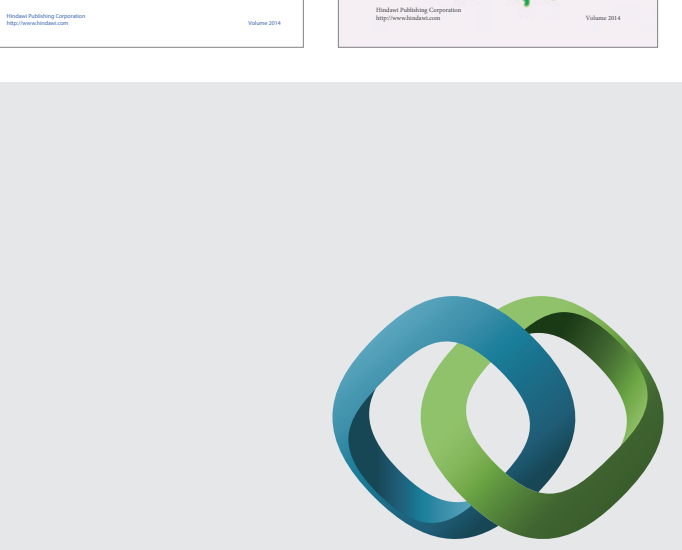

\section{Hindawi}

Submit your manuscripts at

http://www.hindawi.com
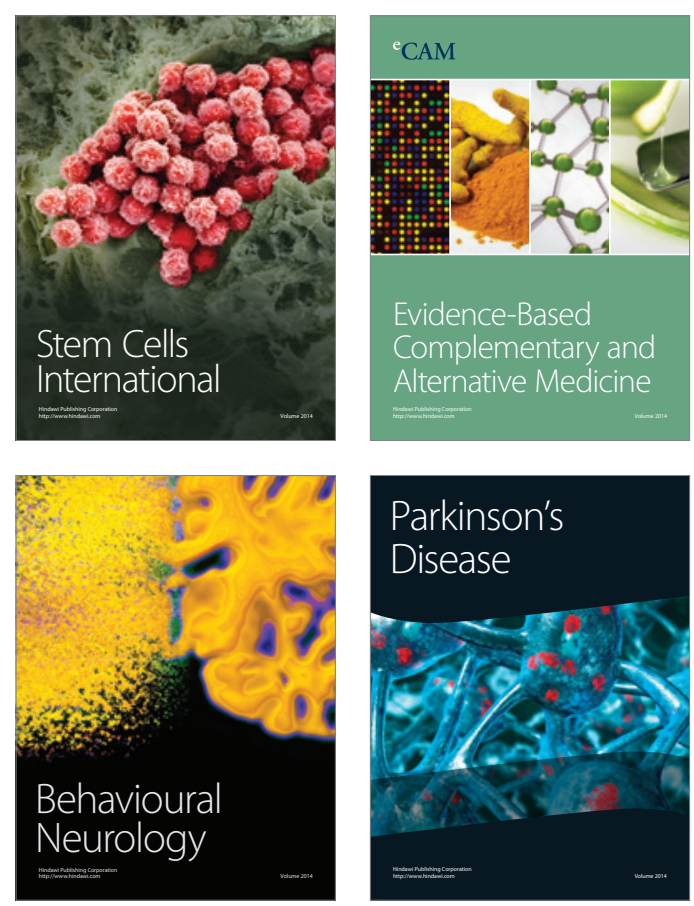

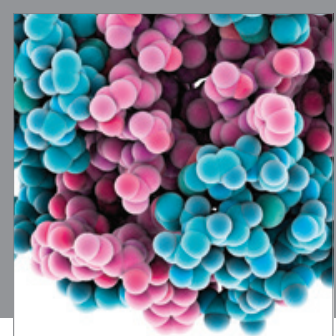

Journal of
Diabetes Research

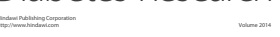

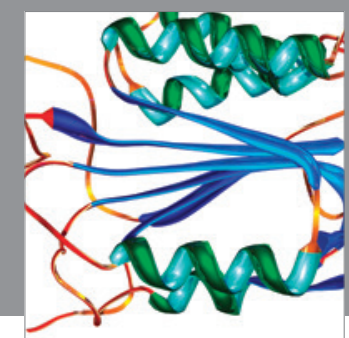

Disease Markers
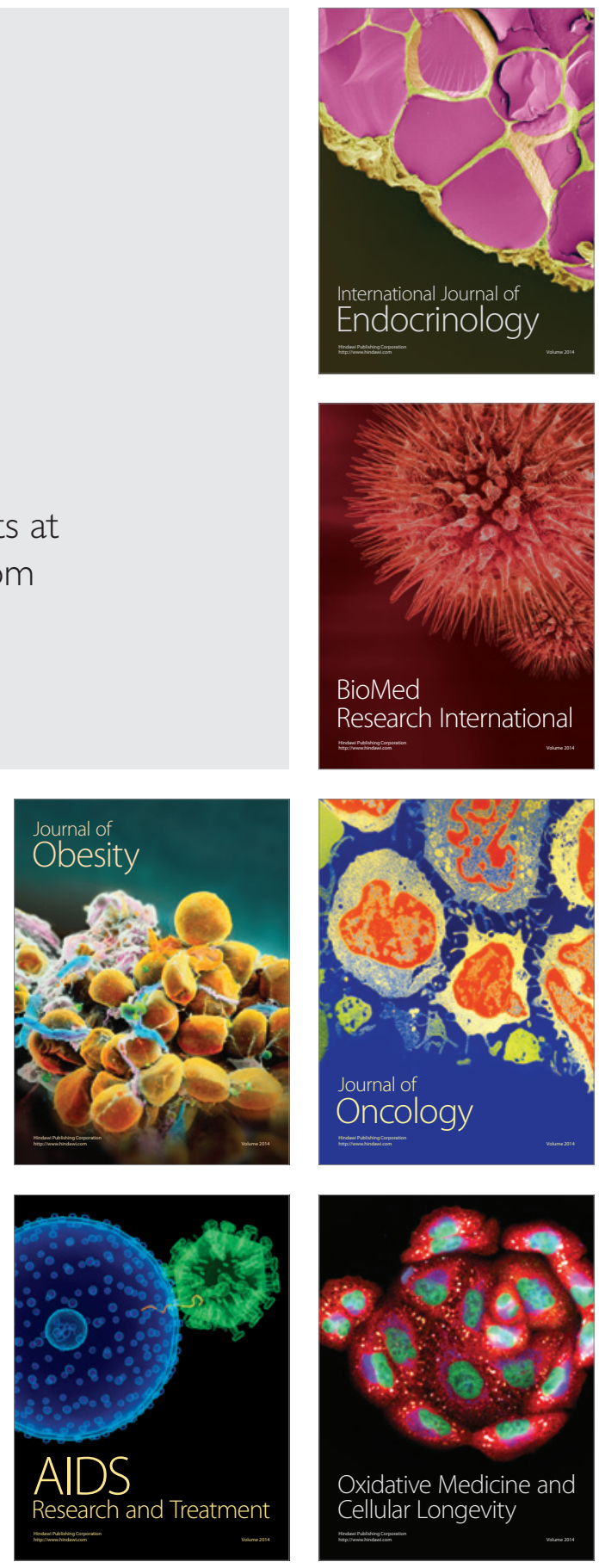